\title{
Examining the Impact of Digital Technologies on Students' Higher Education Outcomes; the Case of the Virtual Learning Environment and Social Media
}

\begin{abstract}
Digital natives is a term used to describe current Higher Education (HE) students, whose lives are proliferated by digital technologies. To cater to needs of this new generation of students, HE institutions increasingly adopt digital tools such as Virtual Learning Environments (VLE) and Social Media (SM). Little is known, however, about the impact of these digital technologies on students' HE outcomes. Drawing from service productivity theories, this study aims to address this gap. Through exploratory sequential mixed research methods, we identify five HE outcomes and reveal that Learning-Oriented Outcomes are the most important in HE even when digital technologies are not used; and these outcomes are further enhanced when students use VLE. Learning-Oriented Outcomes, however, are the least important when SM is used in HE; students tend to prioritise outcomes related to Knowledge Transfer instead. Our research findings derive theoretical and practical contributions, and open up avenues for future research.
\end{abstract}

Keywords: Social Media; Virtual Learning Environment; Higher Education; Productivity; Digital Natives

\section{Introduction}

Digital natives are the new generation of Higher Education (HE) students (Henderson, Selwyn \& Aston, 2017). This group of students is accustomed to digital technologies, and they use them to communicate, establish and maintain social ties, and also to learn. As a result, digital technologies are now an integral part of students' learning experience (Henderson et. al., 2017). In recognition of its importance, the use of digital technologies in HE has become the norm (Helsper \& Eynon, 2010; Lantz-Andersson, et. al., 2013; Tess, 2013). It has also become a point of interest to researchers, who have studied the application and use of digital tools, including but not limited to Virtual Learning Environments (VLE) and Social Media (SM), in the HE context. Most of those 
research efforts have, however, focused on an exploration of factors driving the adoption and use of digital technologies either by faculty or by HE students themselves (Manca \& Ranieri, 2016; Sharm, et. al., 2016). Empirical research examining actual use of these technologies in the HE setting, and specifically the impact of digital technologies on students' HE outcomes, is scarce (Lantz-Andersson et. al., 2013; Whitaker, et. al., 2016; Manca \& Ranieri, 2016). Thus, 'better understanding of the realities of student encounters with digital tools' (Henderson et. al., 2017) is called for. This study aims to respond to this call, and explore the role digital technologies play in HE; and the outcomes and consequences of digital technologies use in the HE context.

Drawing on service productivity theories, we carry out our investigation with a particular focus on two distinct digital technologies used in the HE setting. First, we examine the impact of VLE on students' HE outcomes. VLEs, also referred to as Learning Management Systems, are traditionally used to support teaching and learning. Although digital natives are accustomed to VLE use, they also expect SM to be integrated in the HE setting (Kaplan \& Haenlein, 2016). Social media is defined as 'a group of Internetbased applications that build on the ideological and technological foundations of Web 2.0' (Kaplan and Haenlein, 2010; 61). Unlike VLE, SM has not been developed for educational purposes, and therefore its suitability in HE is brought into question (Tess, 2013). This research thus aims to contribute to the debate on VLE and SM use in HE, and examine the role that these two digital tools have on the perceived importance of HE outcomes.

This paper is organised as follows. First, an overview of digital technologies use in HE is provided, which leads to a discussion concerning VLE and SM use in HE. The theory of service productivity is introduced, which guides an empirical investigation. Next, research methodology and findings of two sequential studies are discussed. This 
study concludes by outlining the theoretical and practical implications derived from this research, its limitations, and suggestions for future research.

\section{Digital Technologies in Higher Education}

The use of digital technologies in Higher Education (HE) is not new. The rapid development of information technologies (IT) in the 1990s marks the first implementation of digital tools in the HE setting (Leidner \& Jarvanpaa, 1993). Since then, the use of digital technologies in HE has thrived, as it has been acknowledged that they can bring a unique set of opportunities for HE teaching and learning (Whitaker, et. al., 2016). Only later has it been recognised that an application of digital technologies in HE has both positive and negative aspects (Whitaker et. al., 2016; Henderson et. al., 2017).

On one hand, there are numerous accounts of effective use of digital technologies in HE. For example, the use of digital tools has been linked to increased student engagement, enhanced problem solving, information seeking and sharing, as well as peer and faculty interaction (Alavi, 1994; Whitaker et. al., 2016; Henderson et. al., 2017). On the other hand, however, it has been pointed out that students learn effectively with or without technologies, and that digital technologies use can have harmful effects on students, leading to detrimental behaviours (Whitaker et. al., 2016). In light of these inconsistent views, researchers caution HE institutions to 'temper their enthusiasm for what might be achieved through technology-enabled learning' (Henderson et. al., 2017), and call for studies to shed light on the impact of digital technologies on HE outcomes.

There are a number of digital technologies used in HE. Developed for educational purposes, the Virtual Learning Environment (VLE) is a 'teacher-centred' technology (Ravenscroft, 2009; Manca \& Ranieri, 2016; Sobaih et. al., 2016) traditionally used in

HE to support teaching and learning (Whitaker et. al., 2016; Sobaih et. al., 2016). 
Empirical research on VLE use and its impact on student HE experience, however, is fragmented (Lee, 2018). Existing research shows an overwhelmingly positive effect of VLE application in the HE setting. For example, Dennen and Spector (2007) reveal a positive impact of VLE, highlighting that its use contributes to students' ability to learn. Lee and Tsai (2011) also report the positive impact of VLE on students' overall learning experience. Cho and Shen (2013) find a positive correlation between the amounts of time spent using VLE and student performance. Mills et. al., (2014) indicate that the advantage of VLE is its ability to bring together both formal and informal learning.

Despite an overall positive effect, the literature points out the limited functionality of VLE relative to unidirectional information flow (Ravenscroft 2009; AlRahmi et. al., 2015; Manca \& Ranieri, 2016; Sobaih et. al., 2016). Building on the ideological foundations of Web 2.0 (Kaplan \& Haenlein, 2010), SM addresses the limitations of VLE by providing opportunities for two-way exchanges (Al-Rahmi et. al., 2015; Sobaih et. al., 2016). Although not developed for educational purposes, SM is readily available and increasingly adopted by HE institutions, as it is seen to be ' $a$ powerful driver of change for teaching and learning practices' (Manca \& Ranieri, 2016), enabling HE institutions to reconnect with digital natives (Junco, 2014).

Although students welcome SM in HE, there is no consensus reached on its impact on students and their HE experience (Giunchiglia et. al., 2018). This is because while some researchers recognise that SM can enhance students' involvement, course participation, and engagement with an assessment task (McCarthy, 2010; Irvin et. al., 2012; Lantz-Anderson et. al., 2013; Kaplan \& Haenlein, 2011; Kaplan \& Haenlein, 2016), others link its use to destruction and poor time-management (Gao et. al., 2012; Tariq et. al., 2012). Similarly, although SM is recognised as a technology that facilitates notes sharing, which enables students' greater access to information (Ophus \& Abitt, 
2009; Manca \& Ranieri, 2013), concerns have been raised about possible information overload (Gao et. al., 2012). Furthermore, although SM has been recognised as a technology, which increases peer interaction as well as collaborative and active learning (Ajjan \& Hrtshorne, 2008; Gao et. al., 2012; Tess, 2013; Manca \& Ranieri, 2016), Friesen \& Lowe (2011) criticise SM use by highlighting its inability to foster debate and disagreement, both of which are crucial elements of learning. Finally, although Pasek et. al. (2009) note the positive impact of SM on students' academic achievements, other researchers disagree with this view, citing the detrimental effect of SM use on students' performance (Paul et. al., 2012; Kirshner \& Karpinski, 2010, Meier et. al., 2016).

In light of those contrasting views on SM use in $\mathrm{HE}$, scholars argue that since SM has not been developed to support teaching and learning, it should not be adopted and used by HE institutions (Tess, 2013). Instead, the decision to do so should be driven by the overall suitability of the technology to the HE setting, rather than on its availability. SM aptness however, comes into question, as Irvin et. al., (2012) and Sobaih et. al., (2016) reveal that students do not believe that SM actually assists them in learning. Thus although students reportedly demand SM use in HE (Kaplan \& Haenlein, 2016), they struggle to make a connection between SM use and HE outcomes (Tess, 2013; Jong et. al., 2014; Hrastinski \& Aghaee, 2012; Au et. al., 2015). In light of these conflicting research findings, Madge et. al., (2009) warn HE against 'over-privileging' SM when it comes to actual pedagogical purposes, as empirical evidence assessing SM use in HE is lacking (Tess, 2013; Henderson et. al., 2017). In order to contribute to this debate, this study draws on productivity theories to reveal the outcomes and consequences of digital technology use in the HE context. 


\section{Higher Education Productivity}

Productivity is a key factor of success in every organisation (Jääskeläinen \& Lönnqvist, 2011), including HE. It is a ratio of output or outcome to input (Ismo et. al., 1998; Johnsen \& Jones, 2004). Most of the existing research has adopted the perspective of the producer on productivity. This however, is deemed insufficient for serviceproviding organisations, such as HE institutions (Parasuraman, 2002), because of the unique characteristics of service; its intangible nature, simultaneous production and service consumption, and active consumer involvement in the service production process (Gronroos \& Ojasal, 2002; Parasuraman, 2002; Anitsal \& Schumann, 2007; Jääskeläinen \& Lönnqvist, 2011).

To account for these service characteristics, and in particular the consumers' role as service co-producer, the term 'service productivity' has been coined (Fitzsimmons, 1985; Parasuraman, 2002; Jääskeläinen \& Lönnqvist, 2011; Anitsal \& Schumann, 2007; Gummesson, 2014). Service productivity refers to a relationship between not only service provider inputs and outcomes, but it is also a ratio of 'the service output experienced by a consumer' and 'the inputs provided by that consumer as a participant in the service production' (Parasuraman, 2002). This divide between the productivity of the service provider and the service consumer is evident in HE, where there are two types of outcomes; direct (e.g. an educational course) and indirect (e.g. learning) (Gardrey, 1988; Jääskeläinen \& Lönnqvist, 2011). The former refers to HE institutional outcomes, while the latter indicates students' HE outcomes as service consumers.

Whilst the consumer role in service productivity is acknowledged as necessary (Janeschek et. al., 2013), the task of measuring consumer productivity is challenging, and has been thus far unachievable (Johnston \& Jones, 2004; Rust \& Hwang, 2012; Parasuraman, 2002; Xue \& Harker 2002; Anitsal \& Schumann, 2007). This is because 
consumers' service productivity outcomes include non-quantifiable outcomes, which are felt and experienced by a consumer (e.g. perception of value for money) (Johnsen \& Jones, 2004; Parasuraman, 2002; Anitsal \& Schumann, 2007). Digital technologies used in service provision add further complexity to the task of measuring productivity.

Due to the proliferation of digital technologies, their application to services was inevitable (Anitsal \& Schumann, 2007). In services, technologies have been used to automate service provision, reducing resources needed in service production (Hwang \& Rust, 2012). In the same way that technologies have transformed the service industry, they are transforming HE, where digital tools reduce the quantity of resources required to produce a service, such as VLE and SM, are perceived to be 'much cost effective' (Whitaker et. al., 2016). Gronroos \& Ojasal (2002) note, however, that 'cost-cutting changes in the resources used may equally well have the opposite effect', and as a result improvements in service producer's productivity may have a negative impact on service productivity outcomes as perceived by a consumer (Fitzsimmons, 1985). This is further confirmed by Parasuraman, (2002), who explicitly notes that 'improvement in one type of productivity is invariably accompanied by deterioration in another'.

To date, there is limited evidence of the impact of digital technologies on consumers' service productivity, and particularly the effect they have on service productivity outcomes. Recently, however, there has been increased interest in understanding how digital technologies affect service provision and service consumption from the consumers' perspective (Martin et. al., 2001; Anitsal \& Schumann, 2007). Since the productivity can vary depending on the context in which it is studied (Tangen, 2005), for the purpose of this research we aim to explore productivity outcomes in the HE setting. We specifically focus on students' productivity as service consumers, as research in HE lacks an understanding of HE outcomes, and the consequence of the use of digital 
technologies in the HE context (Whitaker et. al., 2016). The aims of this study are therefore twofold; to uncover a set of HE outcomes, and to reveal the consequences of the use of digital technologies, namely VLE and SM, on HE outcomes, as perceived by HE students.

\section{Methodology}

To address these study aims we adopt exploratory sequential mixed research methods. Exploratory sequential mixed method research prioritises the qualitative research stage, which informs subsequent quantitative research. The aim of the qualitative study is exploratory in nature; its goal is to identify a set of HE outcomes. For this research stage, the selection of interviewees was based on the following criteria: (1) during the time the study was conducted they had to be HE students, HE faculty or HE support staff; and (2) they had to use VLE and social media for HE education purposes. In order to meet the objectives of this research stage, interviews were carried out during which interviewees were first asked to list a range of HE outputs and then group the identified outcomes into distinct categories. Their responses were verified by reflecting on their use of technologies in the HE setting. The interview guide is provided in Appendix A.

In total, 25 interviewees took part in the study before theoretical saturation was reached, and no new HE outputs or outcomes emerged. Since the use of digital technologies in HE has been largely inconsistent, varying considerably between subjects and disciplines (Selwyn, 2014), in order to obtain a holistic view on HE outcomes and technologies used to support their attainment, the sample included interviewees from across a range of subjects, degrees, and education levels within UK universities. To triangulate qualitative data, the sample included students, faculty, and support staff. This also ensured that all HE outcomes were captured. Accordingly, the sample consisted of 
17 HE students; including 8 undergraduate and 8 postgraduate students, as well as one research student. There were 12 male and 5 female students. The data obtained from the student sample was triangulated with views and opinions from 5 faculty members and 2 members of HE administrative staff (IT support staff).

The second stage of the research is quantitative in nature, and aims to examine HE students' actual use of digital technologies, including VLE and SM, and their impact on HE outcomes. To reveal the consequences of digital technologies use on HE outcomes, we developed a questionnaire survey (see Appendix B) which measures perceived importance of HE outcomes in three different scenarios; in general (i.e. without use of digital technologies), with VLE use, and with use of SM. All HE outcomes in these three scenarios are measured on a seven-point Likert scale. In order to ensure consistency, similar to qualitative research, the quantitative research is conducted using a sample of students from UK Universities. Prior to data collection, the questionnaire was pilot tested to ensure accuracy of the questions asked. We collected data online via forums and social media pages.

In total $229 \mathrm{HE}$ students responded to the questionnaire survey confirming that they were current HE students, and they use both VLE and SM in the HE context. There were 132 female and 94 male respondents, and 3 respondents who preferred not to reveal their gender. The majority of the sample fell into the 18-22 age group category (59\%), with $20 \%$ in the $23-27$ age group. The remaining $30 \%$ of respondents can be classified as mature students (28 year old and older). The respondents were undertaking their studies at four different faculties; Engineering (32.3\%), Business (35.8\%), Humanities (11.4\%), and Science (20.5\%). Over $60 \%$ of respondents were UK nationals, with the remaining group consisting of EU students (11.4\%) and non-EU students (22.7\%). Finally, there was equal distribution of students receiving scholarships (90 students in total), and self- 
sponsored students (91 students in total). 48 participants indicated that their studies were partially funded. Demographic characteristics of respondents are presented in Table 1, below.

$<$ Table 1. Insert here>

\section{Results}

Through the course of the qualitative research, interviewees identified a number of productivity outputs. They then grouped them into five distinct categories of HE outcomes, as presented in Table 2 . In line with service productivity theories, these outputs included both quantifiable and non-quantifiable elements, which are experienced by a student as a service consumer (Johnston \& Jones, 2004; Rust \& Hwang, 2012; Parasuraman, 2002). Overall, five groups of HE outcomes were identified: LearningOriented Outcomes, Cognitive Outcomes, Skills Development Outcomes, Knowledge Transfer Outcomes, and Psychological Outcomes.

The first set of productivity outputs was grouped under the 'Learning-Oriented' category of HE outcomes. This category of HE outcomes included productivity outputs directly related to students' learning, in line with Jääskeläinen \& Lönnqvist, (2011). These Learning-Oriented outputs included both quantifiable elements such as degree and grades, as well as non-quantifiable elements, such as employability potential and career prospects deriving from formal education. Interviewees made a clear distinction between Learning-Oriented outcomes, and outputs grouped under the Cognitive Outcomes category. Cognitive Outcomes included productivity outputs that are felt and experienced by students throughout the course of their education. These are subject knowledge and overall HE experience. The third category of HE outcomes was Skills Development 
Outcomes. Here, interviewees identified a number of skills ranging from project and team management to interpersonal skills. In addition to learning and cognitive outcomes, and outcomes related to skills development, interviewees noted the importance of internships and network relationships established with an industry. These two outputs were grouped under the Knowledge Transfer category. Finally, Psychological Outcomes, including confidence building and feelings of satisfaction, were also recognised as imperative outputs of students' HE experience. The list of HE outcomes and their respective outputs is provided in Table 2 below.

$<$ Table 2. Insert here>

Finally, throughout the course of the qualitative research stage, interviewees confirmed that there are various technologies used in HE. Regardless of the wide range of technologies used, however, the interviewees unanimously agreed that VLE and SM are among the most frequently used digital tools in the HE setting.

The findings of the qualitative research informed the quantitative research stage, during which descriptive analysis was performed to reveal the consequence of use of digital technologies on HE outcomes, as presented in Table 2. To address this research aim, first the relative importance of HE outcomes was examined by calculating the normalised weight $(N W)$ using Equation (1) when $n$ is equal to the total number of HE outcomes $(n=5)$.

$N W_{i}=\frac{R_{i}}{\sum_{j=1}^{n} R_{j}} \forall i=1 \ldots n$

The results of the $N W$ calculation (see Table 3) reveal that the perceived importance of HE outcomes varied across all three scenarios: in general (i.e. without use 
of digital technologies), with VLE use, and with use of SM. Based on the obtained results of the $N W$ calculation, Learning-Oriented Outcomes are the most important HE outcomes when digital technologies are not used $(N W=0.211)$, while HE outcomes related to Knowledge Transfer are the least important $(N W=0.184)$. The results show that the use of VLE enhances students' perception of the relative importance of Learning-Oriented Outcomes $(N W=0.215)$. The use of VLE also increases the relative importance of Knowledge Transfer Outcomes, however the results of our data analysis reveal that Knowledge Transfer Outcomes remain the least important HE outcome when VLE is used $(N W=0.191)$. Students' perceived importance of HE outcomes changes drastically when SM is used. The results of the $N W$ calculation show that when students use SM they perceive Knowledge Transfer to be the most important outcome of their HE experience $(N W=0.215)$, while Learning-Oriented Outcomes and Cognitive Outcomes are perceived to be the least important ( $N W=0.197$ and $N W=0.193$, respectively).

\section{< Table 3. Insert here>}

Next, in order to reveal the consequences of using digital technologies in HE, taking the $N W$ in the first scenario when digital technologies are not used (i.e. in general) as datum, the sensitivity of HE outcomes $i$ towards VLE and SM are calculated using Equation (2) and Equation (3) respectively, where $n=5$.

$$
\begin{gathered}
S_{V L E}^{i}=\frac{N W_{V L E}^{i}-N W_{\text {General }}^{i}}{N W_{\text {General }}^{i}} \times 100 \% \forall i=1 . . . n \\
S_{S M}^{i}=\frac{N W_{S M}^{i}-N W_{\text {General }}^{i}}{N W_{\text {General }}^{i}} \times 100 \% \forall i=1 . . . n
\end{gathered}
$$


The results of sensitivity analysis presented in Table 4 reveal that students' perception of the relative importance of Learning-Oriented Outcomes can be further enhanced by VLE use ( $S=2.03$ ); its perceived importance, however, decreases when SM is used in HE ( $S=-6.66)$. Similar to Learning-Oriented Outcomes, the use of VLE can enhance students' perception of Cognitive Outcomes $(S=0.15)$, while SM use has the opposite effect ( $S=-6.82)$. The results reveal that Skills Development and Psychological Outcomes are the most sensitive to digital technologies used in the HE setting. The relative importance of Skills Development decreases when VLE is used $(S=-3.51$,) and when SM is used $(S=-1.60)$. Similarly, VLE and SM use have a detrimental impact on Psychological Outcomes ( $S=-3.51$ and $S=-1.60$, respectively). Finally, the perceived importance of Knowledge Transfer outcomes can be enhanced with digital technologies, particularly when students use SM $(S=17.22)$

In order to add depth to the investigation, individual outputs of each HE outcome are examined according to their perceived importance using Equation (1), where $n$ is equal to the total number of outputs of a given HE outcome. The sensitivity of element $i$ of a given HE outcome towards VLE and SM is calculated using Equation (2) and Equation (3).

The results presented in Table 4 show that, within the Learning-Oriented Outcomes category, the Degree is the most important productivity output when digital technologies are not used $(N W=0.176)$, and when students use VLE $(N W=0.177)$. When students use SM however, Career Prospects becomes the most important output $(N W=0.177)$. The sensitivity analysis reveals that VLE use has the most positive impact on Feedback received $(S=8.88)$, but its use has a detrimental effect on both Employability $(S=-9.50)$ and Career Prospects $(S=-8.64)$. SM use has a positive impact on Work 
Portfolio $(S=4.94)$ and Career Prospects $(S=4.94)$. SM use has a negative impact on Degree $(S=-5.50)$ and Grades $(S=-5.02)$.

Within the Cognitive Outcomes category, Knowledge appears to be the most important output in all three scenarios considered; in general $(N W=0.509)$, with VLE use $(N W=0.542)$, and with the use of SM $(N W=0.515)$. The results of the sensitivity analysis reveal that Knowledge can be further enhanced when students use VLE $(S=6.35)$, however its use appears to have detrimental effect on students' HE experience $(S=-6.60)$.

Among the Skills Development Outcomes, Problem Solving outputs appear to be perceived as the most important when students do not use digital technologies $(N W=0.173)$, as well as when they use VLE $(N W=0.171)$. Equally important to Problem Solving are Project Management skills when students use VLE ( $N W=0.171)$. SM use appears to have a detrimental effect on Problem Solving ( $S=-6.98)$. A detrimental effect of SM use is also observed on students' Practical skills development ( $S=-12.25)$. The use of SM, however, is perceived to be the most important when developing Team Management skills $(N W=0.182)$.

Industrial connections appear to be the most important within the Knowledge Transfer category. The $N W$ results show that students perceive Industrial Connections to be the most important in the general scenario $(N W=0.507)$, and when they use SM $(N W=0.515)$.

Finally, within the Psychological Outcomes category, all identified outputs appear to have equal $N W$, ranging from $N W=0.120$ to $N W=0.130$ in all three scenarios considered. The sensitivity analysis, however, shows that Confidence is the most sensitive output when VLE is used ( $S=-7.56)$, while SM use has a negative impact on Professionalism $(S=-451)$ and Effort $(S=-3.12)$. 


\section{Discussion and Conclusion}

Drawing from service productivity theory, this study set out to reveal the outcomes and consequences of digital technology use in the HE context. Through exploratory sequential mixed research methodology, we reveal a broad range of HE outcomes, and their relative outputs, that students recognise. These include Learning-Oriented, Cognitive, and Psychological outcomes, as well as those related to Skills Development and Knowledge Transfer. We show that students perceive Learning-Oriented outcomes as the most important of their HE experience. This seems to be in line with previous research, which notes learning as a key outcome of HE (Gardrey, 1988; Jääskeläinen \& Lönnqvist, 2011). Specifically, students appear to prioritise Degree as a key indicator of the achievement of HE outcomes. This perceived importance of Learning-Oriented outcomes, including Degree, is further enhanced when student use VLE. Since VLE has been developed to support students' learning, this research aligns with previous research findings confirming that VLE fulfils its task (Lee, 2018; Lee \& Tsai, 2011; Cho \& Shen, 2013).

In contrast with VLE use, the findings of this research reveals that when students use SM, Learning-Oriented outcomes are perceived to be least important. Previous research notes that SM has not been developed for educational purposes, and thus its use to achieve Learning-Oriented outcomes might be limited (Tess, 2013). Our findings reveal, however, that when students use SM they tend to prioritise HE outcomes related to knowledge transfer. We show that SM use appears to enhance students' industry connections. This significant role of SM use in knowledge transfer seems to be directly related to the nature and functionality of SM, which has been developed to establish and 
maintain connections, rather than to support HE learning and teaching. The findings of this research therefore extends those of Roblyer et. al., (2010), who note that SM enables students' effective communication and career networking opportunities, as well as those of Jong et. al. (2014), who note that students use SM to enhance their social connections, but seldom for educational purposes.

Finally, this study reveals that digital technologies, including VLE and SM, have a detrimental impact on students' skills development and a range of psychological outcomes. In response to Henderson et. al. (2017)'s question, therefore, we note that although digital technologies can assist HE students in attaining learning, cognitive and knowledge transfer outcomes, their use has negative impact on students' achievement of skills development and psychological outcomes.

The findings of this research have a number of theoretical and practical implications. First, this study contributes to the literature by addressing a call by Henderson et. al. (2017) for studies on the outcomes and consequences of digital technologies use in HE. Through the course of this research we reveal that there is a wide range of HE outcomes related to students' HE experience. These include learning and cognitive outcomes, as well as outcomes related to specific skills development, knowledge transfer, and a set of psychological skills. This research therefore broadens our understanding of the range of HE outcomes for students during their HE experience. We also show that while VLE can support learning and cognitive outcomes, SM supports students in their efforts to engage with industry. We reveals that both VLE and SM use have a detrimental impact on skills development and a range of psychological outcomes, including confidence and satisfaction.

Second, we reveal that not all HE outcomes are equally valued by HE students. Students tend to prioritise learning-oriented outcomes, and the attainment of a degree in 
particular, while knowledge transfer outcomes appear to be the least important. We show that digital technologies can have a varied impact on HE outcomes. Thus, this research also contributes to the understanding of consequences of VLE and SM use in HE. Through the course of this research we have shown that VLE can enhance students' perception of the importance of learning-oriented outcomes, while SM use has an opposite effect. In contrast, SM use enhances students' perception of the importance of knowledge transfer outcomes, while they appear to be the least important when students use VLE.

Finally, this research contributes to the debate on the application of digital tools in the HE context. It provides direct comparison of two distinct digital technologies used in HE, and their impact on HE outcomes. Thus far, Schroeder and Greenbowe (2009) are among the few scholars to engage in comparative research of digital technologies use in HE, revealing significant differences in which VLE and SM are used in HE. We expand on this research and identify the impact of VLE and SM use on HE outcomes.

In addition to theoretical contributions, this research finds direct practical implications for HE institutions as well as HE students. Our research reveals that there are a number of HE outcomes deriving from the HE experience. HE institutions are encouraged to communicate a wide range of these outcomes to students. We also encourage HE institutions to use VLE and SM strategically. Based on the findings of this research, we recommend that HE institutions use VLE to support students' learningoriented outcomes, and we discourage SM use as a digital tool to support such outcomes. Instead, we encourage HE institutions and HE students to use SM to strengthen their connections with industry, which will also enhance knowledge transfer outcomes. We caution HE institutions and students against using digital tools in an effort to enhance 
skills development and psychological outcomes, as the use of VLE and SM can have detrimental effect.

This research has some limitations, which we want to acknowledge. First, although we build on productivity theories, we only examine HE students' productivity outcomes. We encourage future research to examine students' inputs. Furthermore, qualitative research, which would provide in-depth evaluation of the role of VLE and social media and their impact on identified HE outcomes, is needed. Second, we carried out this research on UK-based universities, and thus the findings of this research may not be transferable to different country contexts and educational systems. We encourage research to assess HE outcomes in different HE contexts. Finally, we examine the impact of two digital technologies on HE outcomes, namely VLE and SM. Research assessing student engagement with VLE and SM, as well as possible differences in digital technologies use across subject areas is recommended. We would welcome research examining the impact of Massive Open Online Courses and other technology-mediated environments on HE outcomes. 


\section{References}

Ajjan, H. \& Hartshorne, R. (2008). Investigating faculty decisions to adopt web 2.0 technologies: Theory and empirical tests. The Internet and Higher Education, 11(2), $71-80$.

Al-Rahmi, W., Othman, M., Yusof, L. \& Musa, M. (2015). Using social media as a tool for improving academic performance through collaborative learning in Malaysian higher education. Review of European Studies, 7, 265-273.

Alavi, M. (1994). Computer-mediated collaborative learning: An empirical evaluation. Management Information Systems Quarterly, 18, 159-174.

Anitsal, I. \& Schumann, D.W. (2007). Toward a Conceptualization of Customer Productivity: The Customer's Perspective on Transforming Customer Labor into Customer Outcomes Using Technology-Based Self-Service Options. Journal of Marketing Theory and Practice, 15(4), 349-363.

Au, M., Lam, J. \& Chan, R. (2015). Social media education: barriers and critical issues. In Technology in education. Transforming educational practices with technology. Springer Berlin Heidelberg, 199-205.

Cho, M.H. \& Shen, D. (2013). Self-regulation in online learning. Distance Education, 34(3), 290- 301.

Dennen, V.P. \& Spector, J.M. (2007). Preparing Educational Technology Leaders: Reflections on the Past, Present, and Future. Educational Technology, 47(4), 512.

Fenwick, T. (2016). Social media, professionalism and higher education: a sociomaterial consideration. Studies in Higher Education, 41(4), 664-677.

Fitzsimmons, J. (1985). Consumer Productivity and Productivity in Service Operations' Interfaces, 15(3), 60-67. 
Friesen, N. \& Lowe, S. (2011). The questionable promise of social media for education: Connective learning and the commercial imperative. Journal of Computer Assisted Learning, 28(3), 183-194.

Gao, F., Luo, T. \& Zhang, K. (2012). Tweeting for learning: a critical analysis of research on microblogging in education published in 2008-2011. British Journal of Educational Technology, 43(5), 783-801.

Gadrey, J. (1988). Rethinking output in services, The Service Industries Journal, $8(1), 67-76$.

Giunchiglia, F., Zeni, M., Gobbi, E., Bignotti, E. \& Bison, I. (2018). Mobile social media usage and academic performance. Computers in Human Behaviour, 82, 177- 185.

Gronroos, C. \& Ojasal K., (2002). Service productivity. Towards a conceptualization of the transformation of inputs into economic results in services. Journal of Business Research, 57(4), 414- 423.

Gummesson, E. (2014). Productivity, quality and relationship marketing in service operations. International Journal of Contemporary Hospitality Management, 26(5), 656-662.

Helsper, E.J. \& Eynon, R. (2010). Digital natives: where is the evidence? British Educational Research Journal. 36(3), 503-520.

Henderson, M., Selwyn, N. \& Aston, R. (2017). What works and why? Student perceptions of 'useful' digital technology in university teaching and learning, Studies in Higher Education, 42:8, 1567-1579.

Hrastinski, S. \& Aghaee, N.M. (2012). How are campus students using social media to support their studies? An explorative interview study. Education and Information Technologies, 17(4), 451-464. 
Ismo, V., Raija, J. \& Uolevi, L. (1998). 'Content and measurement of productivity in service sector. A conceptual analysis with an illustrative case from the insurance business' International Journal of Service Industry Management. 9 (4), 377- 396.

Irwin, C., Ball, L., Desbrow, B. \& Leveritt, M. (2012). Students' perceptions of using Facebook as an interactive learning resource at university. Australasian Journal of Educational Technology, 28(7), 1221-1232.

Jääskeläinen, A. \& Lönnqvist, A. (2011). Public service productivity: how to capture outputs?. International Journal of Public Sector Management, 24 (4), 289-302.

Janeschek, S., Hottum, P., Kicherer, F. \& Bienzeisler, B., (2013). The dynamics of service productivity and value creation: a service life cycle perspective, The Service Industries Journal, 33(3-4), 366-377.

Johnston R. \& Jones P. (2004). 'Service productivity. Towards understanding the relationship between operational and consumer productivity' International Journal of Productivity and Performance Management, 53(3), 201- 213.

Jong, B.S., Lai, C.L., Lin, Y.T., Lin, T.W. \& Liao, Y.S. (2014). An Exploration of the potential educational value of Facebook. Computers in Human Behaviour. 32, 201211.

Junco, R. (2014). Engaging students though social media. Evidence-based practices for use in student affairs. San Francisco, CA: Jossey-Bass.

Kirschner, P.A. \& Karpinski, A.C. (2010). Facebook and academic performance. Computers in Human Behavior, 26(6), 1237-1245.

Kaplan A.M. \& Haenlein, M., (2010). Users of the word, unite! The challenges and opportunities of Social Media. Business Horizons. 53(1), 59-68.

Kaplan, A.M. \& Haenlein, M. (2011). The early bird catches the news: Nine things you should know about micro-blogging. Business Horizons, 54(2), 105—113. 
Kaplan A.,M. \& Haenlein, M., (2016). Higher education and the digital revolution: About MOOCs, SPOCs, social media, and the Cookie Monster. Business Horizons, 59, 441- 450.

Lee, Y. (2018). Effect of uninterrupted time-on-task on students' success in Massive Open Online Courses (MOOCs). Computers in Human Behaviour, 86, 174-180.

Lee, S,W. \& Tsai, C.C. (2011). Students' perceptions of collaboration, selfregulated learning, and information seeking in the context of Internet-based learning and traditional learning. Computers in Human Behaviour. 27(2), 905-914.

Leidner, D. E. \& Jarvenpaa, S. L. (1993). The information age confronts education: Case studies on electronic classrooms. Information Systems Research, 4, 24 54.

Lantz-Andersson, A., Vigmo, S. \& Bowen, R. (2013). Crossing boundaries in Facebook: Students' framing of language learning activities as extended spaces Computer-Supported Collaborative Learning, 8, 293-312.

Madge, C., Meek, J., Wellens, J. \& Hooley, T. (2009). Facebook, social integration and informal learning at university: It is more for socialising and talking to friends about work than for actually doing work. Learning, Media and Technology, 34(2) $141-155$.

Manca, S. \& Ranieri, M. (2013). Is it a tool suitable for learning? A critical review of the literature on Facebook as a technology-enhanced learning environment. Journal of Computer-Assisted Learning, 29(6), 487-504.

Martin, C.R., Horne, D.A., \& Chan, W.S. (2001). A Perspective on Client Productivity in Business-to-Business Consulting Services, International Journal of Service Industry Management, 12 (2), 137-157. 
McCarthy, J. (2010). Blended learning environments: Using social networking sites to enhance the first year experience. Australasian Journal of Educational Technology, 26(6), 729-740.

Meier, A., Reinecke, L. \& Meltzer, C.E. (2016). “Facebocrastination”? predictors of using Facebook for procrastination and its effects on students well-being. Computers in Human Behavior, 64, 65-76.

Mills, L.A., Knezek, G. \& Khaddage, F. (2014). Information seeking, information sharing, and going mobile: Three bridges to informal learning. Computers in Human Behavior, 32, 324-334.

Manca S. \& Ranieri M. (2016). Facebook and the others. Potentials and obstacles of Social Media for teaching in higher education. Computers \& Education. 95, 216- 230.

Ophus, J.D. \& Abbitt, J.T. (2009). Exploring the potential perceptions of social networking systems in university courses. Journal of Online Learning and Teaching, 5(4), 639-648.

Paul, J.A., Baker, H.M. \& Cochran, J.D. (2012). Effect of online social networking on student academic performance. Computers in Human Behavior, 28(6), $2117-2127$.

Pasek, J., More, E. \& Hargittai, E. (2009). Facebook and academic performance. Reconciling a media sensation with data. First Monday, 14(5).

Parasuraman, A. (2002). Service quality and productivity: a synergistic perspective. Managing Service Quality, 12(1), 6-9.

Ravenscroft, A. (2009). Social software, Web 2.0 and learning: status and implications of an evolving paradigm. Journal of Computer Assisted Learning, 25(1), 15. 
Roblyer, M.D., McDaniel, M., Webb, M., Herman, J. \& Witty, V. (2010). Findings on Facebook in higher education: A comparison of college faculty and student uses and perceptions of social networking sites The Internet and Higher Education, 13 (3), 134-140.

Rust R. \& Huang M., (2012). Optimizing Service Productivity. Journal of Marketing, 76(2), 47-66.

Selwyn, N. (2014). Digital Technology and the Contemporary University. London: Routledge.

Sharma, S.K., Joshi, A. \& Sharma, H. (2016). A multi-analytical approach to predict the Facebook usage in higher education. Computers in Human Behaviour, 55, 340-353.

Sobaih, A.E., Moustafa, M.A., Ghandforoush, P. \& Khan, M. (2016). To use or not to use? Social media in higher education in developing countries. Computers in Human Behaviour, 58, 296- 305.

Tangen, S. (2005). Demystifying productivity and performance. International Journal of Productivity and Performance Management, 54(1), 34- 46 .

Tariq, W., Mehboob, M., Khan, M. A. \& Ullah, F. (2012). The impact of social media and social networks on education and students of Pakistan. International Journal of Computer Science Issues, 9, 407-411.

Tess, P.A. (2013). The role of social media in higher education classes (real and virtual) - A literature review. Computers in Human Behaviour, 29, 60-68.

Whitaker J., New J.R. \& Ireland R.D. (2016). MOOCs and the Online Delivery of Business Education What's new? What's not? What now? Academy of Management Learning \& Education, 15(2), 345-365. 
Xue, M. \& Harker P.T. (2002). Customer Efficiency: Concept and Its Impact on E-Business Management, Journal of Service Research, 4 (4), 253-267. 
Table 1. Quantitative research stage- demographic characteristics.

\begin{tabular}{|l|l|l|l|}
\hline & & Count & $\%$ \\
\hline Country & UK & 229 & 100 \\
\hline & Non-UK & 0 & 0 \\
\hline VLE use & YES & 229 & 100 \\
\hline & NO & 0 & 0 \\
\hline SM use & YES & 229 & 100 \\
\hline & NO & 0 & 0 \\
\hline Age & $18-22$ & 135 & 59.0 \\
\hline & $23-27$ & 46 & 20.1 \\
\hline & $28-31$ & 14 & 6.1 \\
\hline & $32-36$ & 21 & 9.1 \\
\hline & 37 and older & 13 & 5.7 \\
\hline Gender & Female & 132 & 57.6 \\
\hline & Male & 94 & 41.0 \\
\hline & Prefer not to tell & 3 & 1.3 \\
\hline Faculty & Engineering & 74 & 32.3 \\
\hline & Business School & 82 & 35.8 \\
\hline & Humanities & 26 & 11.4 \\
\hline & Science & 47 & 20.5 \\
\hline Nationality & UK & 143 & 62.4 \\
\hline & EU & 34 & 14.8 \\
\hline & International (Non-EU) & 52 & 22.7 \\
\hline Scholarship & Full & 90 & 39.3 \\
\hline & Partial & 48 & 21.0 \\
\hline & Self-sponsored & 91 & 39.7 \\
\hline & & & \\
\hline
\end{tabular}


Table 2. HE outcomes

\begin{tabular}{|c|c|}
\hline HE outcome & Productivity outputs \\
\hline \multirow{6}{*}{ Learning-Oriented Outcomes } & Degree \\
\hline & Grades \\
\hline & Feedback \\
\hline & Work Portfolio \\
\hline & Employability Potential \\
\hline & Career Prospects \\
\hline \multirow{2}{*}{ Cognitive Outcomes } & Knowledge \\
\hline & HE Experience \\
\hline \multirow{6}{*}{ Skills Development Outcomes } & Project Management skills \\
\hline & Team Management skills \\
\hline & Problem Solving skills \\
\hline & Interpersonal skills \\
\hline & Practical skills \\
\hline & Presentation skills \\
\hline \multirow{2}{*}{ Knowledge Transfer Outcomes } & Internships \\
\hline & Industry Connections \\
\hline \multirow{8}{*}{ Psychological Outcomes } & Confidence \\
\hline & Satisfaction \\
\hline & Professionalism \\
\hline & Effort \\
\hline & Patience \\
\hline & Enthusiasm \\
\hline & Willingness \\
\hline & Independence \\
\hline
\end{tabular}


Table 3. HE outcomes; perceived importance and outcomes sensitivity

\begin{tabular}{|l|l|l|l|l|l|}
\hline HE outcomes & $N_{\text {General }}$ & $N_{\text {VLE }}$ & $N_{\text {SM }}$ & $S_{V L E}$ & $S_{S M}$ \\
\hline Learning-Oriented Outcomes & 0.211 & 0.215 & 0.197 & 2.03 & -6.66 \\
\hline Cognitive Outcomes & 0.207 & 0.207 & 0.193 & 0.15 & -6.82 \\
\hline Skills Development Outcomes & 0.197 & 0.193 & 0.197 & -2.47 & -0.13 \\
\hline Knowledge Transfer Outcomes & 0.184 & 0.191 & 0.215 & 3.99 & 17.22 \\
\hline Psychological Outcomes & 0.201 & 0.194 & 0.198 & -3.51 & -1.60 \\
\hline
\end{tabular}


Table 4. HE outputs; outputs' perceived importance and outputs' sensitivity

\begin{tabular}{|c|c|c|c|c|c|c|}
\hline & $\mathrm{NW}_{\text {General }}$ & NW VLE & $\mathrm{NW}_{\mathrm{SM}}$ & Average & $S_{V L E}$ & $S_{S M}$ \\
\hline \multicolumn{7}{|c|}{ Learning-Oriented Outcomes } \\
\hline Degree & 0.176 & 0.177 & 0.167 & 0.173 & 0.17 & -5.50 \\
\hline Grades & 0.167 & 0.174 & 0.159 & 0.167 & 3.97 & -5.02 \\
\hline Feedback & 0.160 & 0.175 & 0.162 & 0.166 & 8.88 & 1.17 \\
\hline Work Portfolio & 0.159 & 0.168 & 0.167 & 0.165 & 5.93 & 4.94 \\
\hline Employability Potential & 0.169 & 0.153 & 0.169 & 0.164 & -9.50 & 0.02 \\
\hline Career Prospects & 0.168 & 0.154 & 0.177 & 0.166 & -8.64 & 4.94 \\
\hline \multicolumn{7}{|l|}{ Cognitive Outcomes } \\
\hline Knowledge & 0.509 & 0.542 & 0.515 & 0.522 & 6.35 & 1.18 \\
\hline HE Experience & 0.491 & 0.458 & 0.485 & 0.478 & -6.60 & -1.22 \\
\hline \multicolumn{7}{|c|}{ Skills Development Outcomes } \\
\hline Project Management skills & 0.159 & 0.171 & 0.168 & 0.166 & 7.18 & 5.43 \\
\hline Team Management skills & 0.167 & 0.170 & 0.182 & 0.173 & 1.89 & 8.95 \\
\hline Problem Solving skills & 0.173 & 0.171 & 0.161 & 0.169 & -1.28 & -6.98 \\
\hline Interpersonal skills & 0.168 & 0.160 & 0.177 & 0.168 & -4.99 & 5.37 \\
\hline Practical skills & 0.169 & 0.160 & 0.148 & 0.159 & -4.81 & -12.25 \\
\hline Presentation skills & 0.164 & 0.168 & 0.164 & 0.165 & 2.53 & 0.10 \\
\hline \multicolumn{7}{|c|}{ Knowledge Transfer Outcomes } \\
\hline Internships & 0.493 & 0.500 & 0.485 & 0.493 & 1.42 & -1.59 \\
\hline Industrial Connections & 0.507 & 0.500 & 0.515 & 0.507 & -1.38 & 1.54 \\
\hline \multicolumn{7}{|l|}{ Psychological Outcomes } \\
\hline Confidence & 0.126 & 0.117 & 0.127 & 0.124 & -7.56 & 0.69 \\
\hline
\end{tabular}




\begin{tabular}{|l|l|l|l|l|l|l|}
\hline Satisfaction & 0.123 & 0.125 & 0.127 & 0.125 & 1.46 & 2.95 \\
\hline Professionalism & 0.127 & 0.128 & 0.122 & 0.126 & 0.36 & -4.51 \\
\hline Effort & 0.129 & 0.130 & 0.125 & 0.128 & 0.44 & -3.12 \\
\hline Patience & 0.120 & 0.122 & 0.120 & 0.121 & 2.18 & 0.50 \\
\hline Enthusiasm & 0.123 & 0.122 & 0.127 & 0.124 & -1.10 & 3.05 \\
\hline Willingness & 0.125 & 0.126 & 0.124 & 0.125 & 0.72 & -0.71 \\
\hline Independence & 0.125 & 0.130 & 0.127 & 0.127 & 3.65 & 1.42 \\
\hline
\end{tabular}

Appendix A. Interview guide

- Participant introduction/ assessment to sample selection criteria

- What is your role at the HE?

○ Do you use digital technologies in HE/ which technologies do you use?

- Assessment of HE outputs

○ Can you please provide some examples of HE outputs (tangible/intangible) deriving form HE to students?

- Are there any other HE outputs you can think of?

- Outcomes grouping

○ Can you please group identified HE outputs into categories?

○ How would you name each category? 
Appendix B. Questionnaire survey

1. Please rate the importance of the following OUTPUTS that you can achieve as a University student, where 1- not at all important; 4- neutral, 7- Extremely important

\begin{tabular}{|c|c|c|c|c|c|c|c|}
\hline & $\begin{array}{c}\mathbf{1} \\
\text { Not at all } \\
\text { important }\end{array}$ & 2 & 3 & $\begin{array}{c}\mathbf{4} \\
\text { Neutral }\end{array}$ & 5 & 6 & $\begin{array}{c}\mathbf{7} \\
\text { Extremely } \\
\text { important }\end{array}$ \\
\hline \multicolumn{8}{|c|}{ Learning-Oriented Outcomes } \\
\hline \multicolumn{8}{|l|}{ Degree } \\
\hline \multicolumn{8}{|l|}{ Grades } \\
\hline \multicolumn{8}{|l|}{ Feedback } \\
\hline \multicolumn{8}{|l|}{ Work portfolio } \\
\hline \multicolumn{8}{|c|}{ Employability potential } \\
\hline \multirow{2}{*}{\multicolumn{8}{|c|}{$\begin{array}{l}\text { Career prospects } \\
\text { Cognitive Outcomes }\end{array}$}} \\
\hline & & & & & & & \\
\hline \multicolumn{8}{|c|}{ Knowledge } \\
\hline \multicolumn{8}{|l|}{ HE Experience } \\
\hline \multicolumn{8}{|c|}{ Skills Development Outcomes } \\
\hline \multicolumn{8}{|c|}{ Project management skills } \\
\hline \multicolumn{8}{|c|}{ Team management skills } \\
\hline \multicolumn{8}{|c|}{ Problem solving skills } \\
\hline \multicolumn{8}{|c|}{ Interpersonal skills } \\
\hline \multicolumn{8}{|c|}{ Practical skills } \\
\hline \multirow{2}{*}{\multicolumn{8}{|c|}{\begin{tabular}{l|l} 
Presentation skills & \\
Knowledge Transfer Outcomes
\end{tabular}}} \\
\hline & & & & & & & \\
\hline \multicolumn{8}{|l|}{ Internships } \\
\hline \multicolumn{8}{|c|}{ Industrial connections } \\
\hline \multicolumn{8}{|c|}{ Psychological Outcomes } \\
\hline \multicolumn{8}{|l|}{ Confidence } \\
\hline \multicolumn{8}{|l|}{ Satisfaction } \\
\hline \multicolumn{8}{|c|}{ Professionalism } \\
\hline \multicolumn{8}{|l|}{ Effort } \\
\hline \multicolumn{8}{|l|}{ Patience } \\
\hline \multicolumn{8}{|l|}{ Enthusiasm } \\
\hline \multicolumn{8}{|l|}{ Willingness } \\
\hline Independence & & & & & & & \\
\hline
\end{tabular}

2. Now, please rate the importance of those OUTPUTS that you can achieve as a University student while using Virtual Learning Environment

\begin{tabular}{|l|c|c|c|c|c|c|c|}
\hline & $\begin{array}{c}1 \\
\text { Not at all } \\
\text { important }\end{array}$ & $\mathbf{2}$ & $\mathbf{3}$ & $\begin{array}{c}\mathbf{4} \\
\text { Neutral }\end{array}$ & $\mathbf{5}$ & $\mathbf{6}$ & $\begin{array}{c}\mathbf{7} \\
\text { Extremely } \\
\text { important }\end{array}$ \\
\hline Learning-Oriented Outcomes \\
\hline Degree & & & & & & & \\
\hline Grades & & & & & & & \\
\hline
\end{tabular}




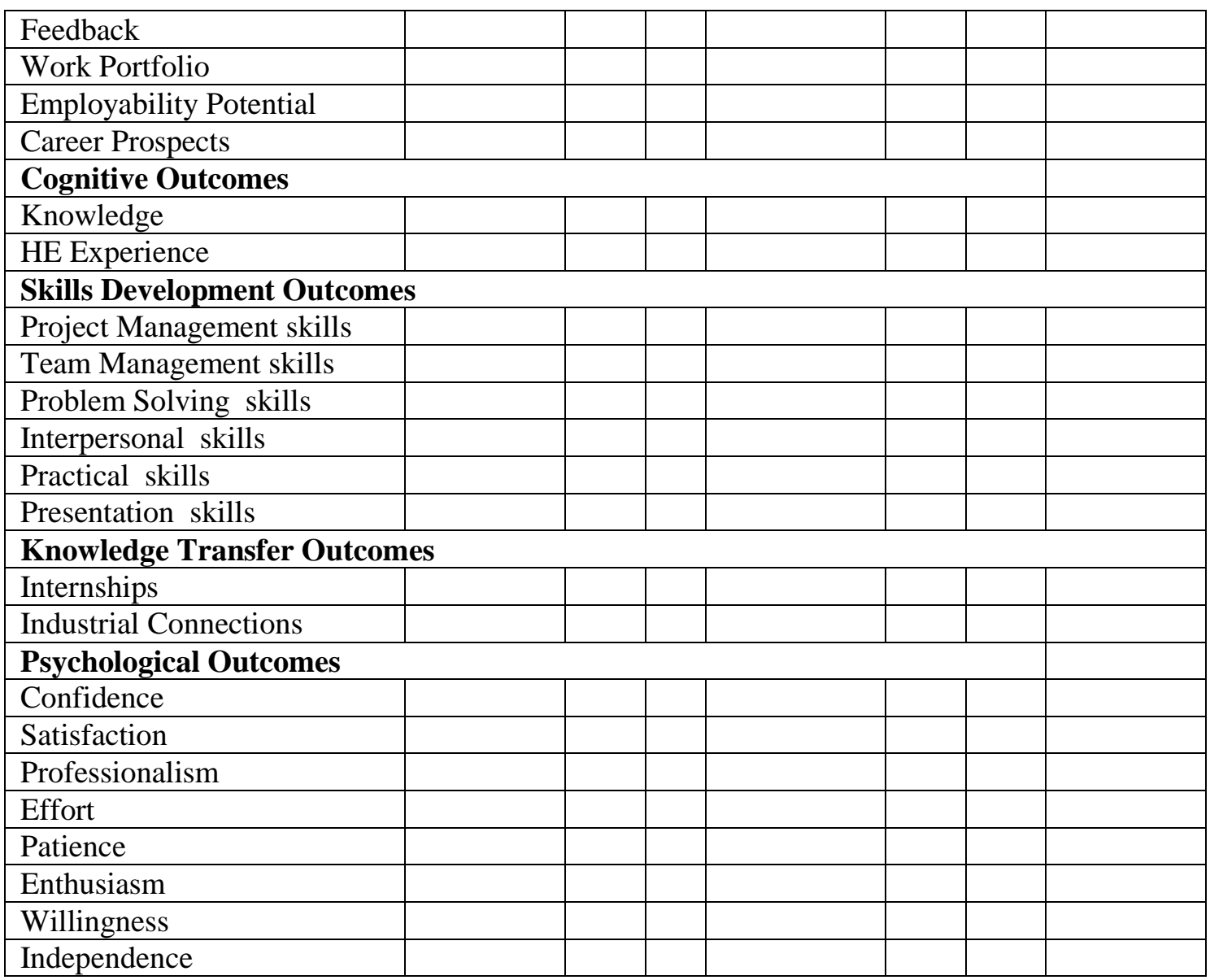

3. Finally, please rate the importance of those OUTPUTS that you can achieve as a University student while using Social Media (including Facebook, Twitter,

LinkedIn, etc.)

\begin{tabular}{|c|c|c|c|c|c|c|c|}
\hline & $\begin{array}{c}\mathbf{1} \\
\text { Not at all } \\
\text { important }\end{array}$ & 2 & 3 & $\begin{array}{c}\mathbf{4} \\
\text { Neutral }\end{array}$ & 5 & 6 & $\begin{array}{c}\mathbf{7} \\
\text { Extremely } \\
\text { important } \\
\end{array}$ \\
\hline \multicolumn{8}{|c|}{ Learning-Oriented Outcomes } \\
\hline \multicolumn{8}{|l|}{ Degree } \\
\hline \multicolumn{8}{|l|}{ Grades } \\
\hline \multicolumn{8}{|l|}{ Feedback } \\
\hline \multicolumn{8}{|l|}{ Work Portfolio } \\
\hline \multicolumn{8}{|l|}{ Employability Potential } \\
\hline \multicolumn{8}{|l|}{ Career Prospects } \\
\hline \multicolumn{8}{|l|}{ Cognitive Outcomes } \\
\hline \multicolumn{8}{|l|}{ Knowledge } \\
\hline \multicolumn{8}{|l|}{ HE Experience } \\
\hline \multicolumn{8}{|c|}{ Skills Development Outcomes } \\
\hline \multicolumn{8}{|l|}{ Project Management skills } \\
\hline \multicolumn{8}{|l|}{ Team Management skills } \\
\hline \multicolumn{8}{|l|}{ Problem Solving skills } \\
\hline Interpersonal skills & & & & & & & \\
\hline
\end{tabular}




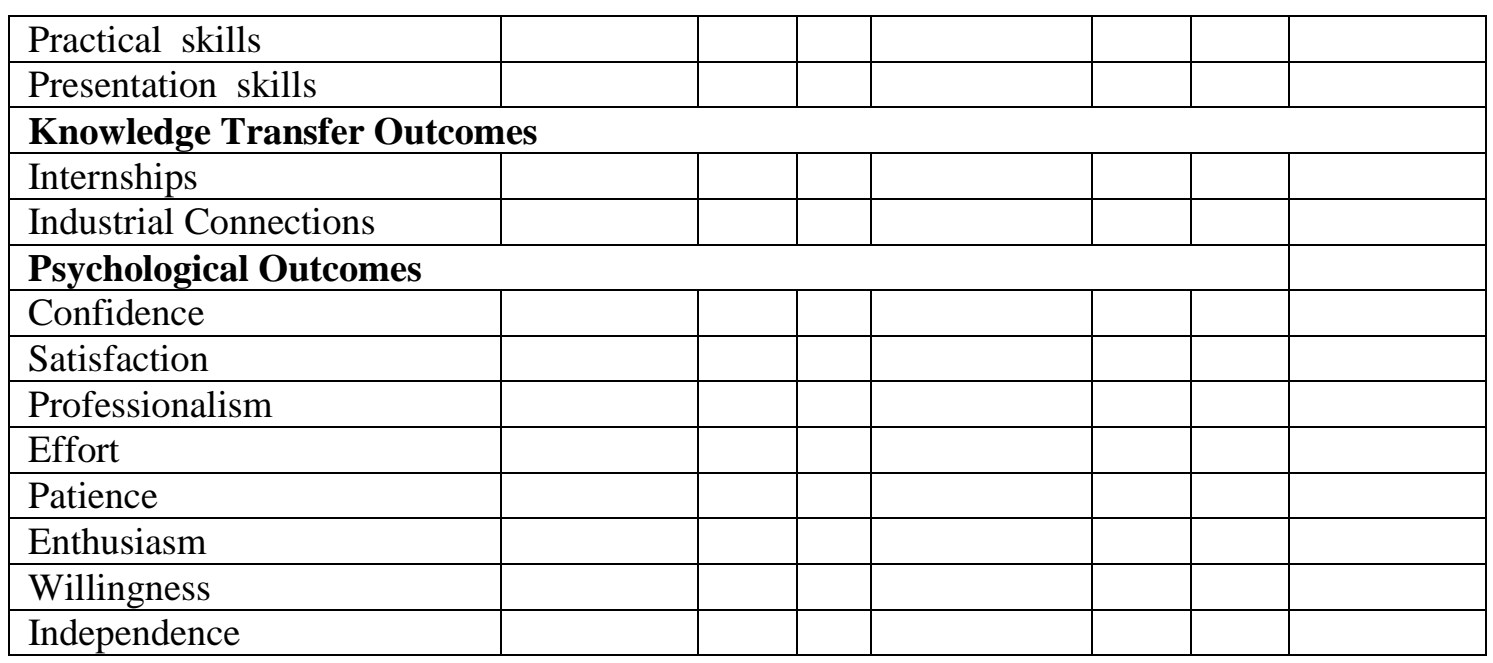

